\title{
ENDOCHRONIC THEORY OF DYNAMIC VISCOPLASTICITY
}

Hsuan-Chi Lin

ANL-83-59

\author{
by
}
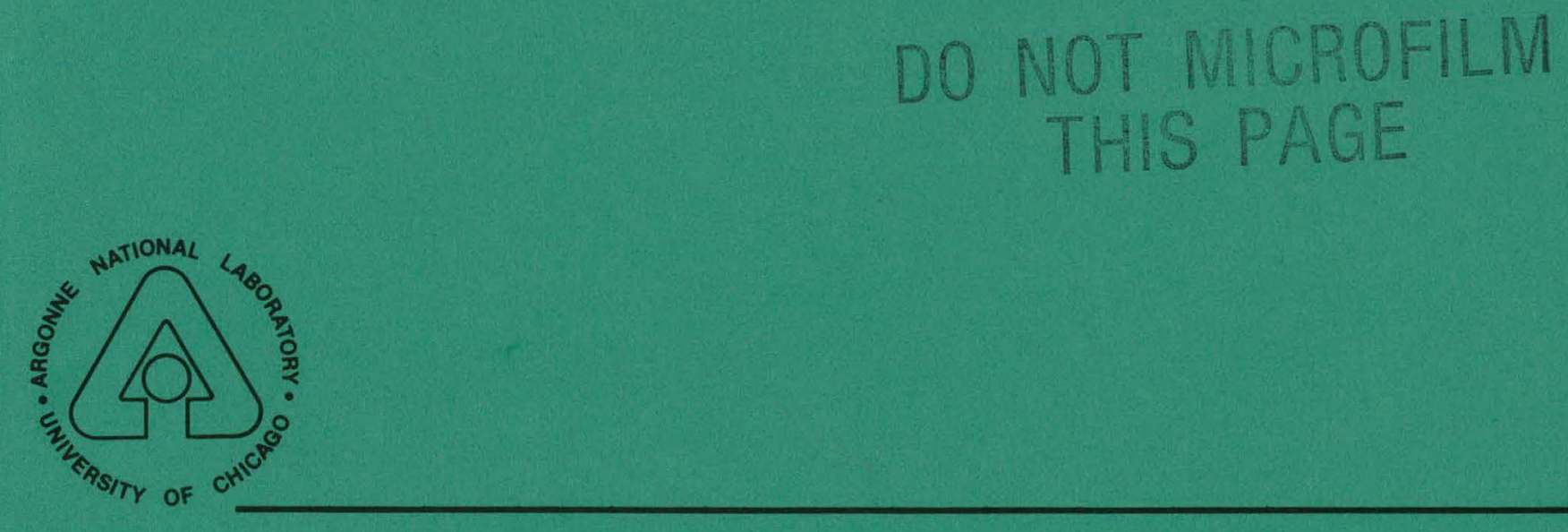

ARGONNE NATIONAL LABORATORY, ARGONNE, ILLINOIS

Operated by THE UNIVERSITY OF CHICAGO for the U. S. DEPARTMENT OF ENERGY under Contract W-31-109-Eng-38 


\section{DISCLAIMER}

This report was prepared as an account of work sponsored by an agency of the United States Government. Neither the United States Government nor any agency Thereof, nor any of their employees, makes any warranty, express or implied, or assumes any legal liability or responsibility for the accuracy, completeness, or usefulness of any information, apparatus, product, or process disclosed, or represents that its use would not infringe privately owned rights. Reference herein to any specific commercial product, process, or service by trade name, trademark, manufacturer, or otherwise does not necessarily constitute or imply its endorsement, recommendation, or favoring by the United States Government or any agency thereof. The views and opinions of authors expressed herein do not necessarily state or reflect those of the United States Government or any agency thereof. 


\section{DISCLAIMER}

Portions of this document may be illegible in electronic image products. Images are produced from the best available original document. 


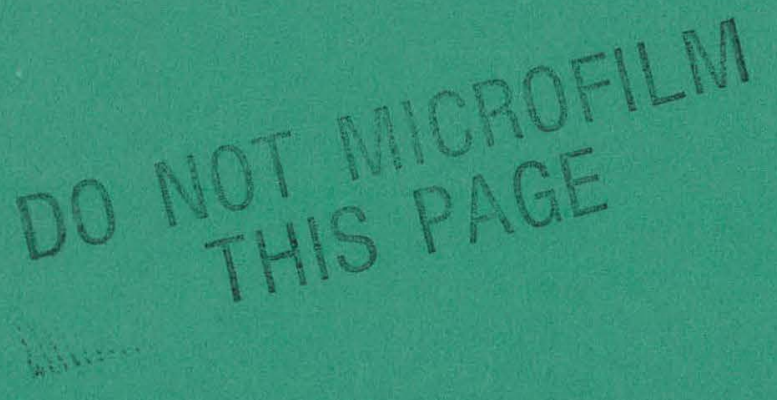

DISCLAIMER

This report was prepared as an account of work sponsored by an agency of the United States Government. Neither the United States Government nor any agency thereof, nor any of their employees, makes any warranty, express or implied, or assumes any legal liability or responsibility for the accuracy, completeness, or usefulness of any information, apparatus, product, or process disclosed, or represents that its use would not infringe privately owned rights. Reference herein to any specific commercial product, process, or service by trade name, trademark, manufacturer, or otherwise, does not necessarily constitute or imply its endorsement, recommendation, or favoring by the United States Government or any agency thereof. The views and opinions of authors expressed herein do not necessarily state or reflect those of the United States Government or any agency thereof.

Printed in the United States of America

Available from

National Technical Information Service

U. S. Department of Commerce

5285 Port Royal Road

Springfield, VA 22161

NTIS price codes

Printed copy: $\mathrm{A} 03$

Microfiche copy: A01 
Distribution Category:

Materials (UC-25)

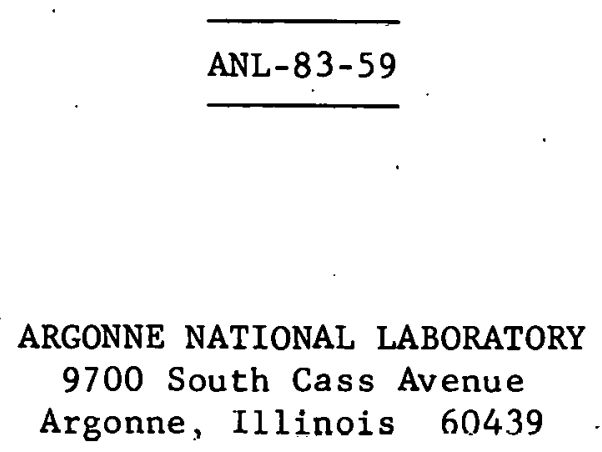

ANL- $-83-59$

DE83 017531

ENDOCHRONIC THEORY OF DYNAMIC VISCOPLASTICITY

by

Hsuan-Chi Lin

Components Technology Division
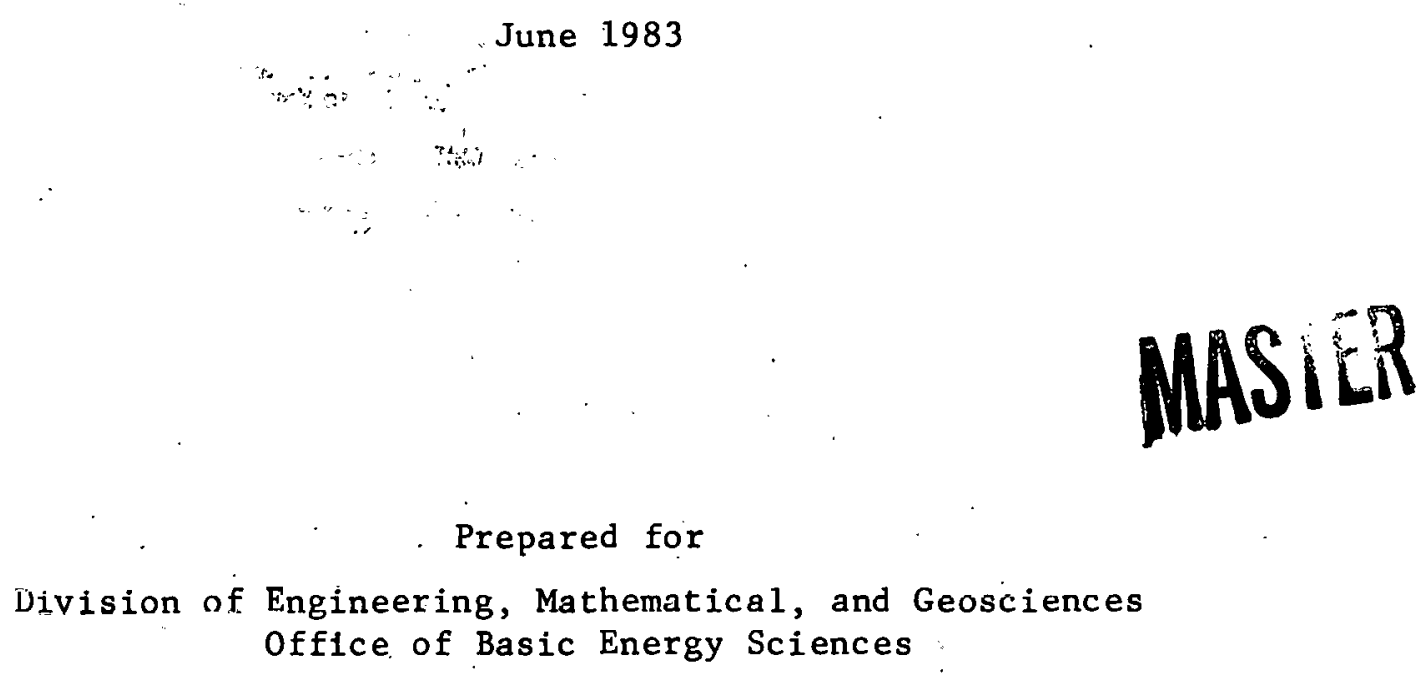

DISTRIBUTION OF THIS OOCUMEAT IS UNLINHRE 


\section{DISCLAIMER}

This report was prepared as an account of work sponsored by an agency of the United States Government. Neither the United States Government nor any agency thereof, nor any of their employees, makes any warranty, express ur imiplied, or aooumes any legal liahility or responsibility for the accuracy, completeness, or usefulness of any information, apparatus, product, or process disclosed, or represents that its use would not infringe privately owned rights. Reference herein to any specitic commercial pruduet, proooso, or servire, by trade name, trademark, manufacturer, or otherwise does not necessarily constitute or imply ils endorsement, recommendation, or favoring by the United States Government or any agency thereof. The views and opinions of authors expressed herein do not necessarily state or rcflect those of the United States Government or any agency thereof. 


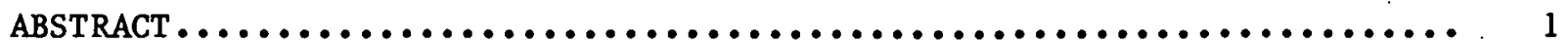

1. INTRODUCTION................................... 2

2. FUNDAMENTAL ENDOCHRONIC THEORY OF VISCOPLASTICITY........... 3

3. NUMERICAL EXAMPLES ............................. 5

3.1 Shallow Spherical Cap Subjected to Step Uniform Pressure Leading............................... 5

3.2 Clamped Circular Plate Subjected to Explosive Loads...... 6

3.3 High Velocity Impact Problem..................... 7

3.4 Crack Propagation in a Pressurized Cylindrical Shell Due to Ductile Failure.......................... 8

3.5 Application to Multidimensional Stress Cases............ 9

4. UNIQUENESS AND STABILITY OF ENDOCHRONIC THEORY............. 10

5. IMPROVED ENDOCHRONIC THEORY $\ldots \ldots \ldots \ldots \ldots \ldots \ldots \ldots \ldots \ldots \ldots \ldots \ldots \ldots \ldots$

6. STRAIN RATE EFFECTS............................. 12

7. VISCOPLASTIC WAVE PROPAGATION UNDER UNIAXIAL STRESS $\ldots \ldots \ldots \ldots \ldots$

8. RECOMMENDATION OF FUTURE WORKS $\ldots \ldots \ldots \ldots \ldots \ldots \ldots \ldots \ldots \ldots \ldots \ldots \ldots$

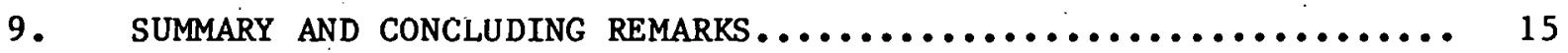

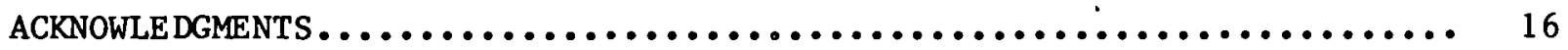

REFERENCES ....................................... 17

APPENDIX: PROJECT PUBLICATTONS . ........................... 19 
1 Dynamic response of spherical cap under uniform external step pressure of 600 psi (plane stress).

2. Dynamic response of impulsively loaded clamped circular plate $(6061-\mathrm{T} 6$ alumi num, Inp $=1.67 \mathrm{~N} . \mathrm{s}) \ldots \ldots \ldots \ldots \ldots \ldots \ldots \ldots \ldots$

3 Comparisons of deformation of impact system for various constitutive laws and time steps........................ 7

4 Crack opening displacement profiles.................... 8

5 Loading-unloading behavior of various $k_{1}$ values for $\alpha$ Ti...... 11

6 Stress-strain curves of $\alpha-\mathrm{Ti}$ for various constant strain-rate..................................... 12

7 Strain-time histories of longitudinal waves in $a-\mathrm{T} 1$,

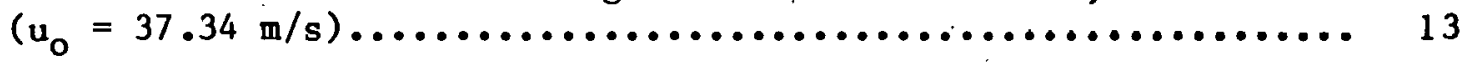




\title{
ENDOCHRONIC THEORY OF DYNAMIC VISCOPLASTICITY
}

by

\author{
Hsuan-Chi Lin
}

\begin{abstract}
This report summarizes the work completed on a project concerned with engineering models in dynamic plasticity. The concept of the endochronlc theory of viscoplasticity and its subsequent improvement are discussed briefly. Applications and extensions of the theory to various dynamic problems are presented. In particular, the strain-rate effect in the improved endochronic theory and its application to wave propagation problems are discussed. Comparing the numerical resulto with other calculations and experimental data, it appears that endochronic theory provides a promising representation of realistic material behavior. At the same time endochronic theory is often numerically more efficient than other formulations.
\end{abstract}




\section{INTRODUCTION}

The general objective of this work was to develop a conceptually sound and computationally efficient continuum basis for describing the dynamic plastic deformation of metals subjected to short-duration, high-intensity loading. Specific attention was directed at refinements and extensions of endochronic viscoplasticity theory [1], that is, on formulations that replace clock time with time-like deformation measures that are intrinsic material properties, and that describe both elastic and plastic response without introduction of a yield surface. Endochronic theory is a phenomenological rather than microscoplc approach, with irreversible thermodynamics as a rallulale. To maximize the cventual utility of theoretical models, the correlation belweu derived constitutive representations and avallable conventional materials data was explored.

Endochronic theory describes material behavior during deformation in terms of an intrinsic time-like variable that is not measured by a clock, but is itself a material property. It has the advantage of representing qualitatively different deformation regimes in terms of one consistent set of field equations. For example, there is no need to introduce a yield criterion to differentiate between elastic and plastic response, although yield can be modeled in the improved theory [2].

This report first provides a brief introduction to the theory, then describes various analytical examples used to validate the derived constitutive laws. A brief discussion is given concerning the work on the stability and uniqueness of the simple endochronic theory in dynamic applications. Next is the improved endochronic theory [2], which eliminates or mitigates the criticisms $[3,4]$ leveled at the earlier formulation about unloading behavior and consequent stability problems. With the accommodation of the strain-rate effect into the improved theory and its application to viscoplastic wave propagation, it is then shown that the Improved theory does widen the predictive scope of the original theory. Some recommendations for future work also are discussed, based on the experience gained during the course of this work. For convenience, a 1ist of publications generated during the course of this project is provided in the Appendix. 


\section{FUNDAMENTAL ENDOCHRONIC THEORY OF VISCOPLAST ICITY}

The endochronic constitutive equations for isotropic materials under isothermal and small-strain conditions can be written as follows:

$$
s_{i j}=2 \int_{0}^{z} \mu\left(z-z^{\prime}\right) \frac{\partial e_{i j}}{\partial z^{\prime}} d z^{\prime},
$$

and

$$
\sigma_{\mathrm{kk}}=3 \mathrm{~K} \varepsilon_{\mathrm{kk}}
$$

where $s_{i j}$ and $e_{1 j}$ are deviatoric parts of the stress and strain tensors $q$ and $\xi ;$ and $\mu(z)$ and $K$ are the heredity functions and the bulk modulus, respectively. The symbol $z$ denotes a positive monotonically increasing intrinsic time scale with respect to a time measure $\zeta$ such that $d z / d \zeta>0$, and

$$
\mathrm{d} \zeta^{2}=\mathrm{P}_{1 \mathrm{jk \ell}} \mathrm{d} \varepsilon_{1 \mathrm{j}} \mathrm{d} \varepsilon_{\mathrm{k} \ell},
$$

where $P_{i j k l}$ is a positive definite fourth-order material tensor that is a metric in strain space. Let the heredity functions be represented by an exponentially decaying function such as $\mu(z)=\mu_{0} e^{-\alpha z}$ to accommodate for the fading memory, and $\mu_{0}$ and $\alpha$ being positive constants. Furthermore, let $\mathrm{dz}=\mathrm{d} \zeta /(1+\beta \zeta)$, where $\beta$ is a positive parameter, to account for the friction aspect of the internal variables for strain-hardening materials. Then the above constitutive equation (1) becomes

$$
2 \mu_{0} \frac{\mathrm{de}}{\mathrm{d} \zeta}=\frac{\alpha \underset{\sim}{\mathrm{s}}}{1+\beta \zeta}+\frac{\mathrm{d}}{\mathrm{d} \zeta} .
$$

Equations (2) and (4) form the basis of the simple endochronic theory. All the material parameters involved can be obtained from the uniaxial stressstrain curve.

As the theory progressed, it was found that the definition of intrinsir. time in Ey. (3) led to difficulties in describing the material behavior during unloading. Since then, Valanis [2] has proposed an improved concept of intrinsic time to overcome these difficulties. In the one-dimensional case, the improved intrinsic time increment $d \zeta$ is defined as

$$
\mathrm{d} \zeta=\left|\mathrm{d} \varepsilon-\mathrm{k}_{1} \frac{\mathrm{d} \sigma}{\mathrm{E}_{0}}\right|
$$


where $k_{1}$ is a positive scalar such that $0 k_{1}<1$, and $E_{0}$ is the elastic modulus. When $k_{1}=0$, the improved intrinsic time reduces to the original definition of intrinsic time, and the theory reverts to the simple endochronic theory. When $\mathrm{k}_{1}=1, \mathrm{Eq}$. (5) reduces to $\mathrm{d} \zeta=\left|\mathrm{d} \varepsilon-\mathrm{d} \sigma / \mathrm{E}_{\mathrm{o}}\right|$, which is the plastic strain increment. Thus the conventional concept of yleld can be obtained within the framework of endochronic theory. 


\section{NUMERICAL EXAMPLES}

The simple endochronic theory of viscoplastictty has been applied to predictions of the inelastic dynamic response of structural systems subjected to various loading conditions. A summary of these efforts follows.

\subsection{SHALLOW SPHERICAL CAP SUBJECTED TO STEP UNIFORM PRESSURE LOADING}

The example studied is of a clamped spherical cap subjected to suddenly applied uniform pressure (4.134 $\mathrm{MPa}$ or $600 \mathrm{ps1}$ ) on its convex surface [5]. The problem is solved by assuming that elther a plane stress or a plane strain condition exists in the direction normal to the midsurface of the cap. The constitutive equations are derived from the endochronic theory for both plane stress and plane strain conditions. Figure 1 shows typlcal results in terms of the apex displacement of the cap obtained by using the classical elastic, classical elastoplastic, and endochronic constitutive laws for the plane stress case. The results using endochronic constitutive

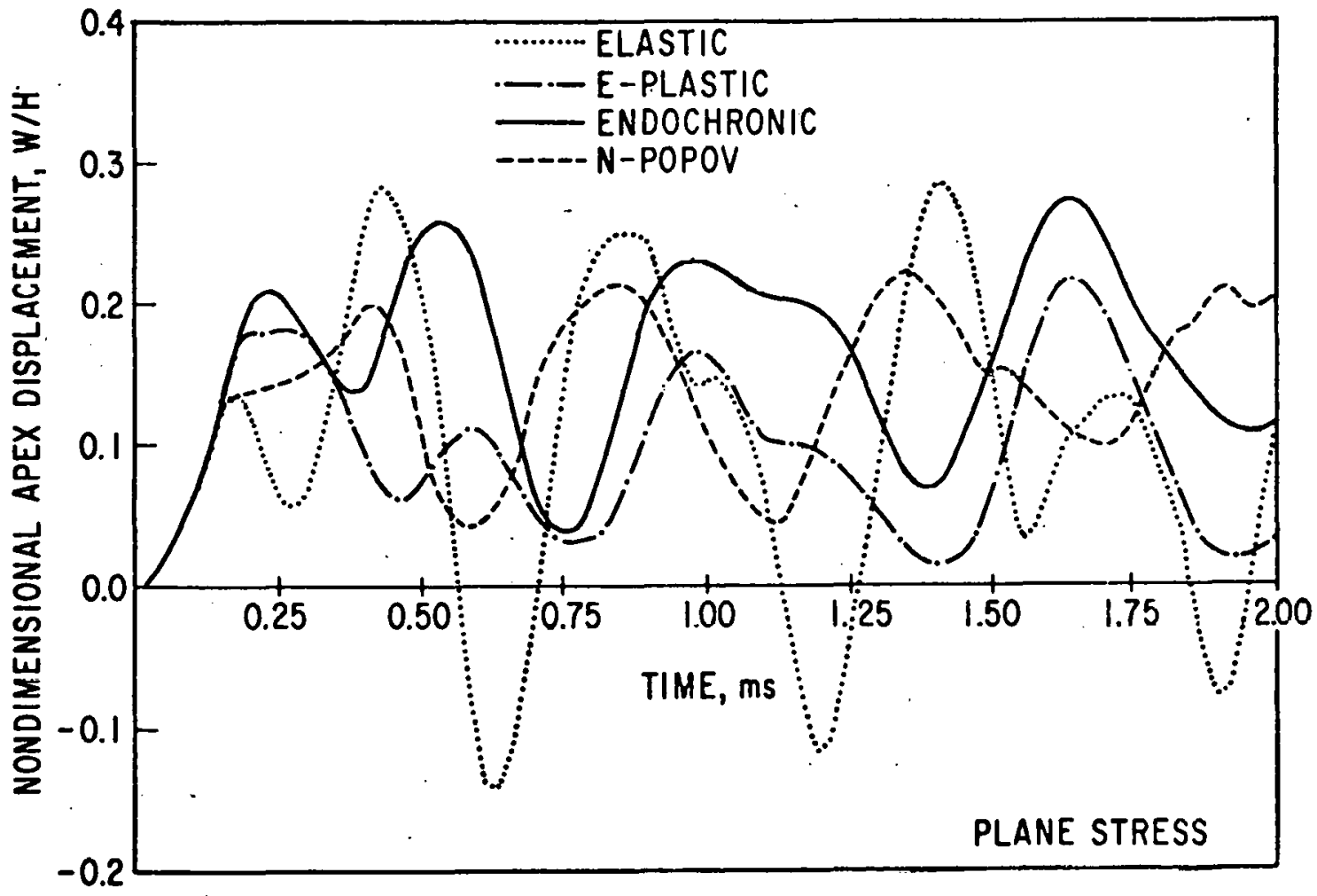

Figure 1 Dynamic response of spherical cap under uniform external step pressure of 600 psi (plane stress) 
law compare favorably with the conventional elastoplastic isotropic workhardening assumption as far as dynamic response at the apex of the cap is concerned. However, the mean value of displacement is higher and the amplitude of vibration is smaller in the endochronic results than in the classical theory. In other words, the use of the endochronic theory produces a softer model compared to the models generated by the classical theories. This, in a sense, would make the endochronic theory more conservative than the classical approach in many design situations.

\subsection{CLAMPED CIRCULAR PLATE. SUBJECTED TO EXPLOS IVE LOADS}

A hardening structural system was examined on a clawped circular thin plate loaded laterally over a circular central region with sheet explosive $[5,6]$. Figure 2. shnws the resulting nondimensional apex displacement versus time for 6061-T6 aluminum with applied impulse equal to 1.67 N.s. The experimental results together with the finite-difference results of the DEPROSS code also are shown in the figure. All numerical results presented here are in good agreement with the experimental data during the inftial loading stage. However, the displacements using endochronic theory are consistently higher than both experimental and DEPKOSS results after the initial peak. This is attributed to the larger unloading slope of the stress-strain curve based on simple endochronic theory compared to that for elastic unloading.

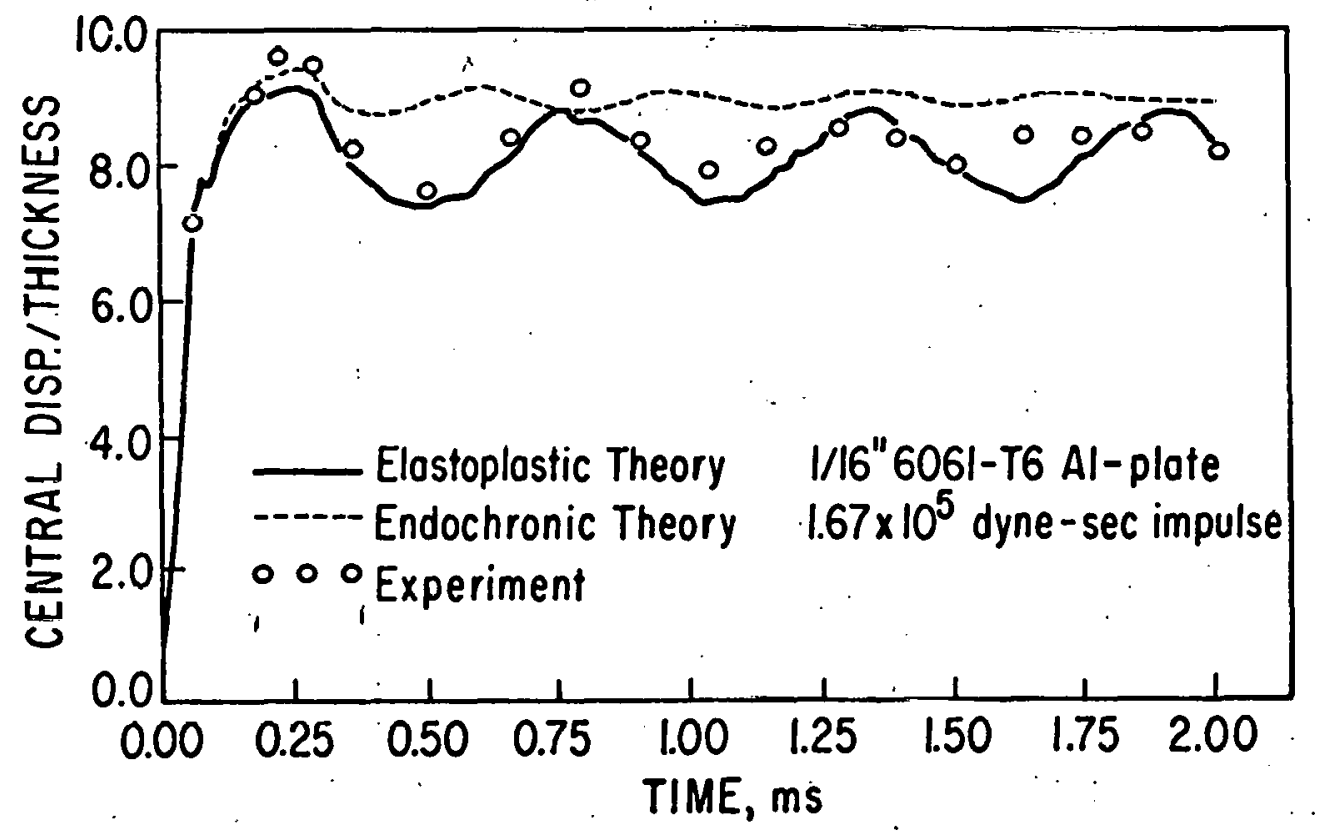

Figure 2 Dynamic responses of impulsively loaded clamped circular plate (6061-T6 aluminum, Inp $=1.67 \mathrm{~N} \cdot \mathrm{s})$ 


\subsection{HIGH-VELOCITY IMPACT PROBLEM}

This example considered a nickel cylinder impacting on an aluminum plate at $500 \mathrm{~m} / \mathrm{s}$ [5]. The cylinder was assumed to be bonded to the plate such that no slippage could occur between the two surfaces, and the material was not allowed to fracture. Because severe distortions are expected for this type of problem, the constitutive laws relating the volumetric stress and strain were modifled using the nonlinear Mle-Gruneisen equation of state, which relates the hydrostatic pressure and volumetric change. This was done both for the elastoplastic and endochronic models. The problem was solved using the corotational finite element method. The comparisons of results for various time integrations steps are shown in Fig. 3 up to the time the models failed. ("Failure" is defined as the point when an element is so severely deformed that its area or volume becomes a negative value.) The deformation patterns of the elastoplastic model are highly sensitive to the time steps used. When a large time step (say, $\Delta t=0.1 \mu \mathrm{s}$ ) is used, the deformation pattern looks clearly like a plug formation type. As the time step decreases, a new line of severe distortion occurs along a line about $45^{\circ}$ from the axial direction. In other words, the severe deformation patterns are composed of only one "slip line" when the time step ls large and two "slip lines" when the time steps are small.

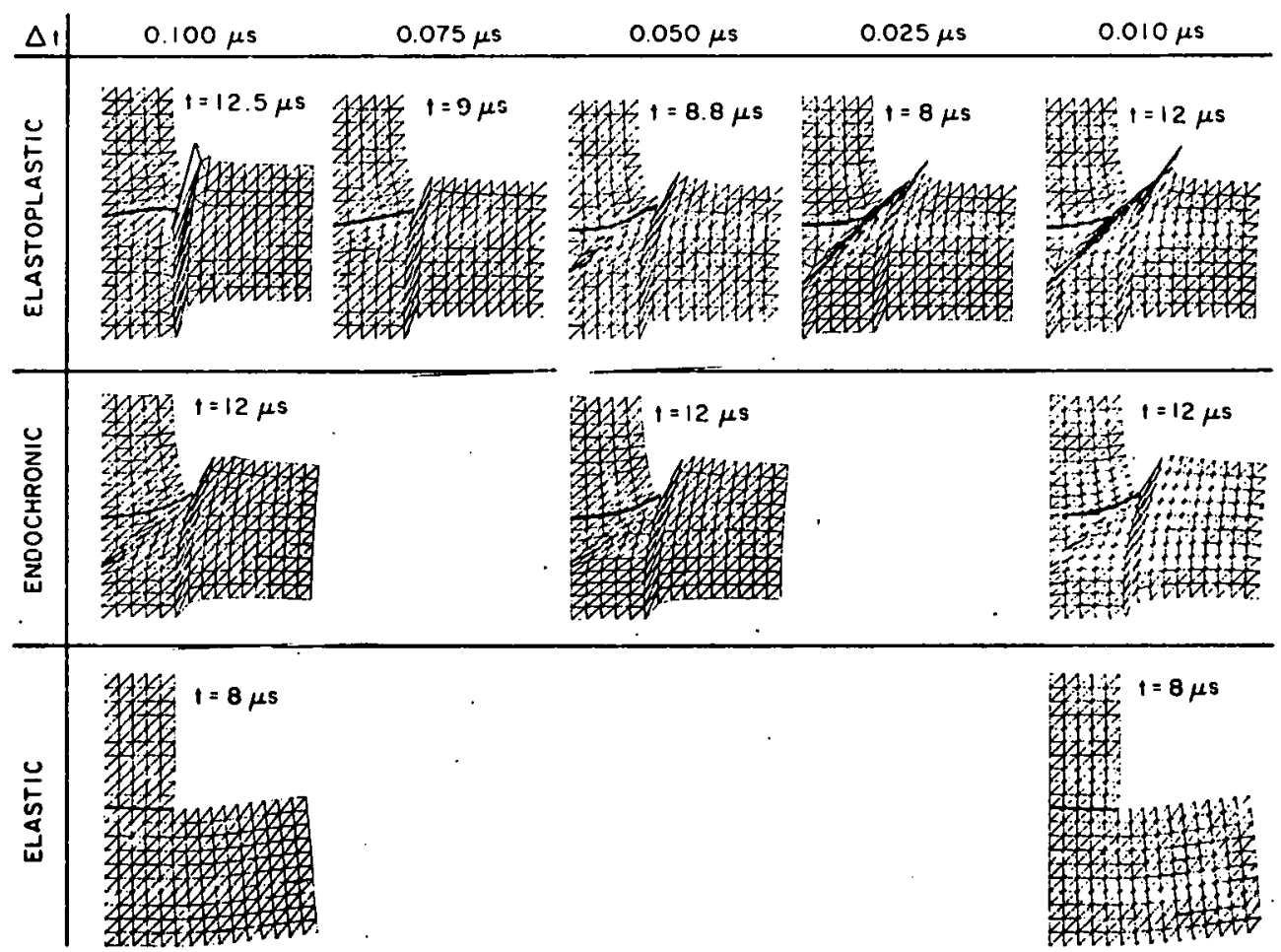

Figure. 3 Comparisons of deformation of 1mpact system for various constitutive laws and time steps 
The comparison of elastoplastic and elastic models reveals that this anomalous behavior is caused by the plasticity of the model; because almost identical results are obtained when the elastic constitutive law is used with different time steps. The second row in Fig. 3 shows the results using the endochronic constitutive law.'Almost identical results are obtained for the entire range of different time steps used in the endochronic case; the deformation patterns observed in the endochronic model are always composed of two "slip lines", one along $45^{\circ}$ and another along $90^{\circ}$, irrespective of the time steps used. Therefore, a larger time step can be used in the endochronic theory, thus reducing the computational time compared to the conventional elastoplasticity model. It has been shown that using the endochronic theory results in about $30 \%$ savings in computational time compared to classical elastoplastic models for the same accuracy [5].

\subsection{CRACK PROPAGATION IN A PRESSURIZED CYLINDRICAL SHELL DUE TO DUCT ILE FAILURE}

The endochronic theory was applied to the study of dynamic motion of a longitudinal through-crack along a pressurized cylindrical shell [7]. Numerical calculations were carried out for a suddenly introduced axial through-crack in the wall of the pressurized pipe that is subsequently allowed to propagate according to prescribed ductile fracture criteria. The finite-difference method was used for numerical computation. Figure 4 shows

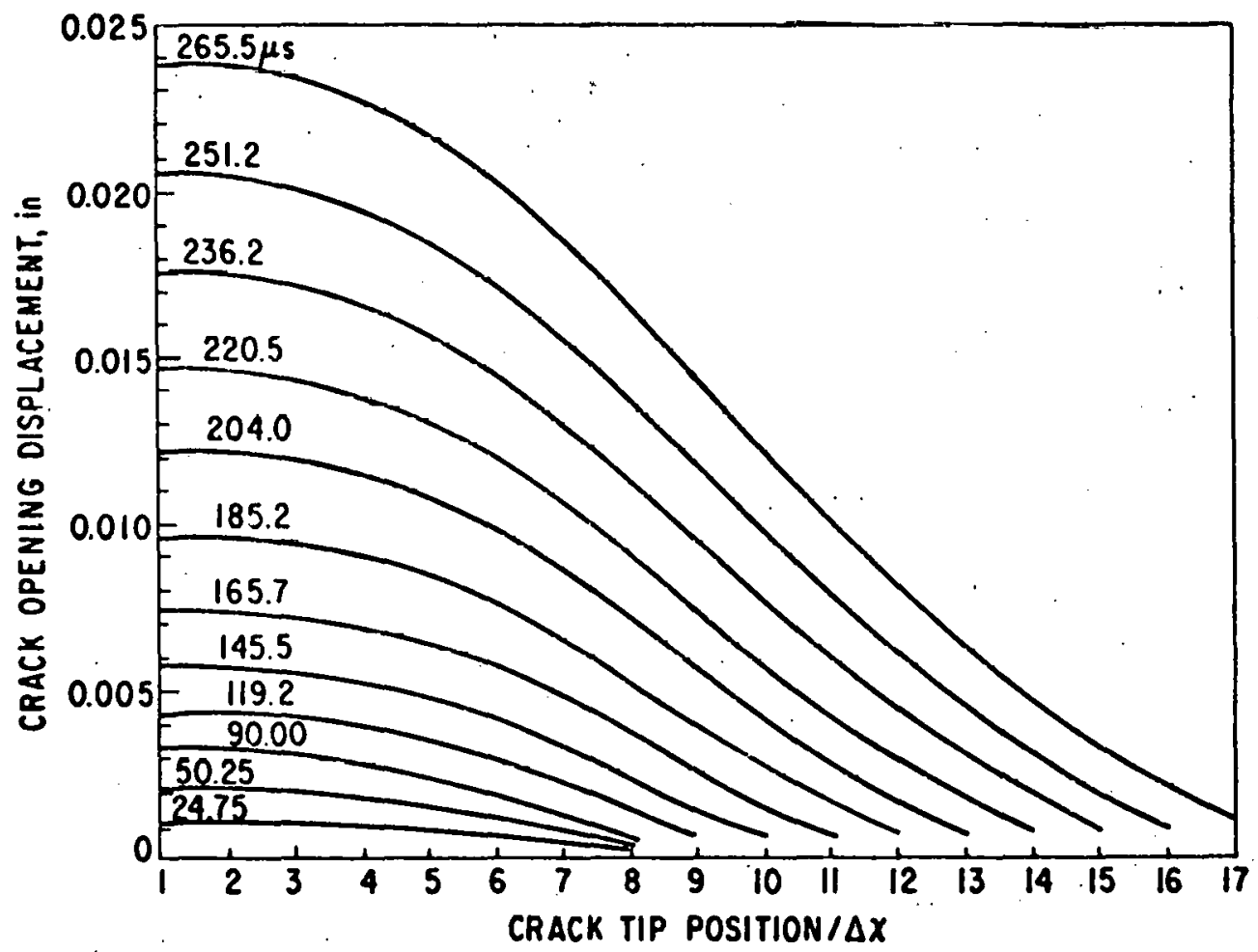

Figure 4 Crack opening displacement profiles 
the profile of one-quarter of the crack opening displacement at various time steps just before the crack tip extended for an internal pressure of 3.474 $\mathrm{MPa}$ in an A533B steel pipe. The resulting profile is smooth in both spatial and temporal coordinates; this is in good agreement with many reported results. There are no intermittency phenomena occurring in this calculation. This is in contrast to some other investigators who have reported the existence of such intermittent motions. Crack tip movement and the hoop stress resultant history also were presented in [7] at various times. Due to the assumption of a constant internal pressure, no crack arrest was observed in the example.

\subsection{APPLICATION TO MULTIDIMENSIONAL STRESS CASES}

The simple endochronic theory was successfully applied to the study of axially symmetric motion of a finite circular cylindrical shell silhjected to an arbitrary piessure transient acting at 1ts inner surface [8]. The endochronic constitutive laws for thin shells were derived. The governing equations were then solved by means of the characteristics method. The problem of a thick-shell was also studied and solved numerically by the method of nearcharacteristics [9]. Many numerical results were obtained $[8,9]$ for specific boundary conditions and prescribed pressure loading histories.

Multidimensional stress-state endochronic theory formulations were used to study the transverse behavior of a rod subjected to uniaxial loading and to analyze the behavior of a plate subjected to an in-plane biaxial stress state under static conditions [10]. Again, very satisfactory results were obtained. Therefore, in general, it can be sald that the simple endochronic model with a simple relaxation function can be applied sur.essfully to certain problems, although it may exhibit undesirable behavior for other problems. 


\section{UNIQUENESS AND STABILITY OF ENDOCHRONIC THEORY}

As the endochronic theory developed, it was found that the unloading slope of the uniaxial stress-strain curve is larger than the elastic unloading curve, as observed in most of the experiments for metallic materials. As a result, Sandler [3] and Rivlin [4] argued that the theory does not satisfy Drucker's postulate and hence the material would be unstable and nonuniqueness of solutions could result. Several numerical and analytical analyses were performed [11] to evaluate the uniqueness and stability of solutions using some simple mechanical models whose material behaviors are governed by endochronic plasticity. It was found that the simple endochronic material "creeps" under the action of applied forces for dynamic problems, which leads to "instab111ry" In the sense of Sandler's argument. However, it was also shown that the endochronic solution is at least as unique as that of the classical elastoplasticity. It is also evident from all the above-mentioned works that there are no numerical difficulties assoclated with the endochronic theory. Edelstein [12] reviewed the main criticisms of the endochronic theory by Sandler and Rivin and the response of its defenders. As stated in Reference 12, the observations and analysis of Sandler and Rivlin, while very Ingenious, were addressed only to the simplest, special case of the 1971 theory, namely, that of a single term hereditary modulus. Even with this, the endochronic theory does not seem to have been fatally discredited. To the contrary, Sandler and Riviin may actually have helped promote the theory by raising those questions, the answers to which will ultimately put it on a sounder physical and mathematical foundation. 


\section{IMPROVED ENDOCHRONIC THEORY}

As mentioned earlier, due to the larger unloading slope in the endochronic uniaxial stress-strain curve compared to the conventional elastic unloading, the simple endochronic theory falled to predict closed hysteresis loops for small unloading-reloading processes under an uniaxial stress condition. Later on, Valanis [2] discovered that the discrepancy between endochronic prediction and the experimental observation was due to a thermodynamic cause and specifically related to the intrinsic time rate of dissipation at the onset of unloading or reloading. The energy of dissipation upon unloading is essentially zero for elastic unloading, and Valanis found that if the measure of intrinsic time is defined in terms of the increment of plastic strain, the dissipation rate at the onset of unloading and reloading is zero. Therefore, it is more appropriate to adopt the plastic strain increment than the previous total strain increment as the measure of intrinsic time.

With the plastic strain as an intrinsic time measure, it was possible to prove that a yield surface exists under special conditions, and that kinematic hardening rules are a consequence of the improved endochronic theory. To show the influence of parameter $k_{1}$ in Eq. 5, a set of stressstrain curves for $\alpha$ titanium is presented in Fig. 5 for $k_{1}=0.05,0.5$, and 0.95 [13-16]. For $k_{1}=0.05$, it can be seen that the unloading-reloading behavior is of the type expected in simple endochronic theory; for $\mathrm{k}_{1}=$ 0.95, the unloading-reloading behavior approaches elastic behavior. Therefore, $k_{1}=0.95$ provides a good approximation for elastic unloading behavior and subsequent reloading behavior.

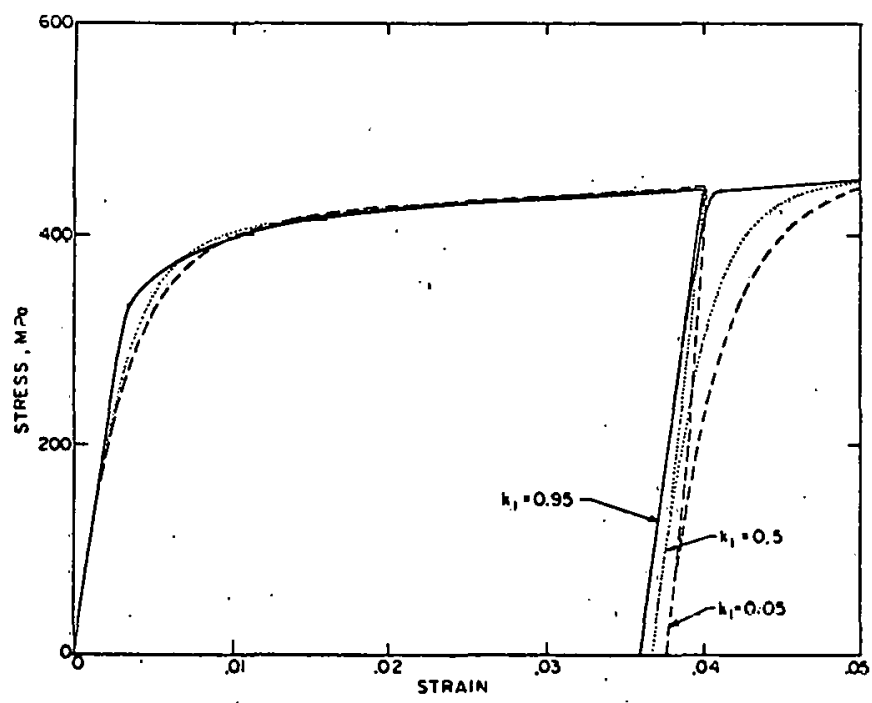

Figure 5 Loading-unloading behavior of various $k_{1}$ values for $\alpha-T 1$ 


\section{STRAIN RATE EFFECTS}

The influence of strain rate on the mechanical response of materials has been studied extensively in the classical theory of plasticity. It is clear that many practical dynamic problems can be treated satisfactorily only if the rate dependence of plastic material behavior is considered. Although various constitutive equations have been proposed in the past to accommodate the strain rate effect by introducing the concept of dynamic overstress, more research is needed for a consensus among proponents of the various theories. In the framework of the improved endochronic theory, we have proposed [13, 16] a logarithmic law, in either linear or quadratic form, of strain-rate function to describe strain rate ranging from $10^{-5}$ to $10^{3} \mathrm{~s}^{-1}$. Figure 5 shows the stress-strain curves of $\alpha$-titanium at various constant strain rates using the proposed law. It 18 gratifying to note that the proposed strain-rate function is adequate to duscilbe widc range of strain rates for many engineering materials.

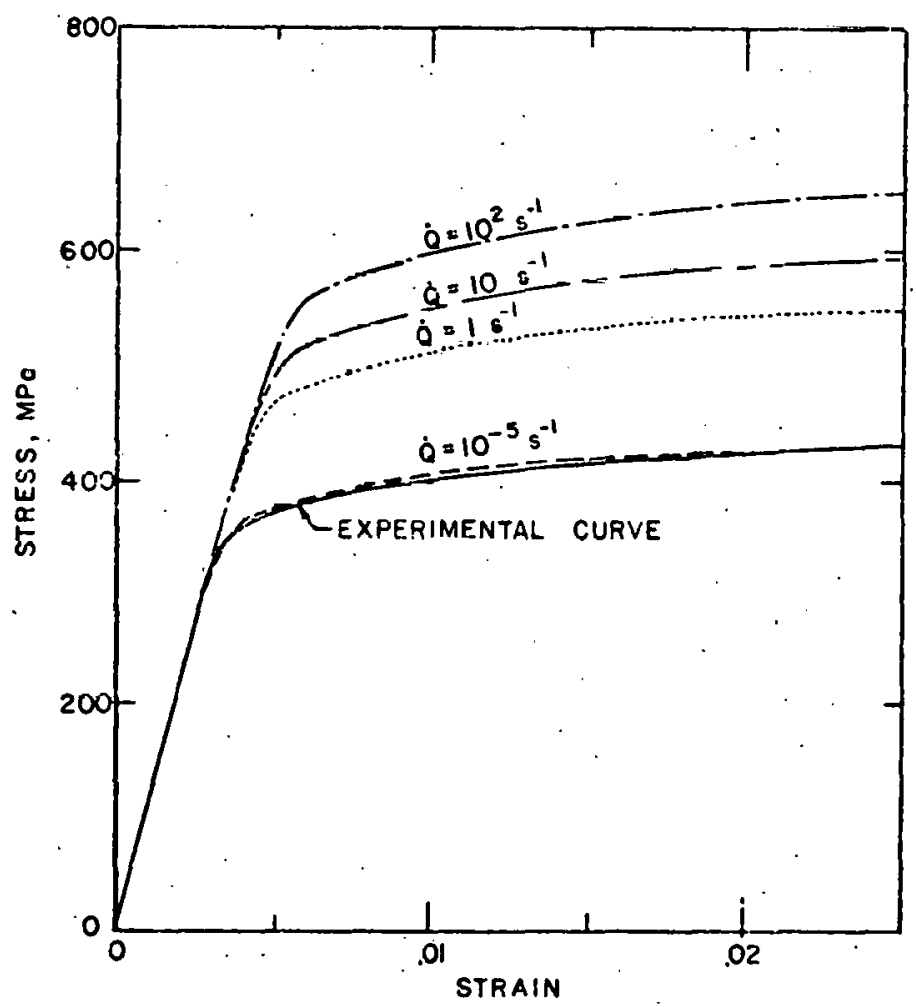

F1gure 6 Stress-strain curves of - $\alpha$ T1 for various constant strain-rate 


\section{VISCOPLASTIC WAVE PROPAGATION UNDER UNIAXIAL STRESS}

To validate the effect of the proposed strain-rate function on dynamic material response using the improved intrinsic time measure, the problem of longitudinal wave propagation in a thin rod was studied [13-16]. The specific problem is to have an elastic hitter impacting on a semi-infinite, slender, thin-walled, a-titanium tube through a transmitter. The constitutive law for uniaxial stress with strain-rate effect was derived to solve the initial-boundary-value problem of wave propagation. The numerical results (method of characteristics) using the improved endochronic time formulation were compared with theoretical and experimental results from the literature; this comparison is shown in. Figure 7 in terms of strain-time profile for a prescribed impact velocity on the end of the tube for $u_{0}=$ $37.34 \mathrm{~m} / \mathrm{s}$. The qualitative features of the computed and experimental profiles are clearly in good agreement. Note that not only the loading wave but also the unloading wave compared favorably with the experimental results, which could not be obtained using the simple endochronic theory. For more detalled discussion on these matters see Reference 13.

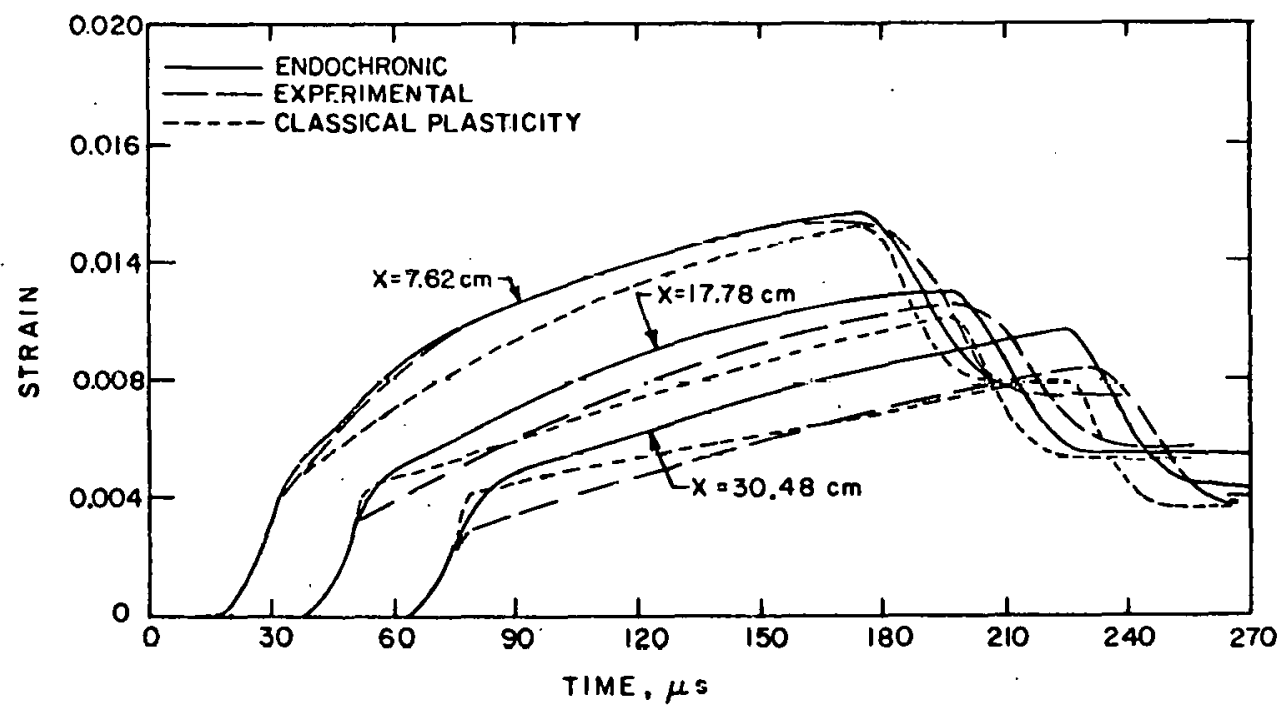

Figure 7 Strain-time Histories of Longitudinal waves in $\alpha \mathrm{T} 1,\left(\mathrm{u}_{0}=37.34 \mathrm{~m} / \mathrm{s}\right)$ 


\section{RECOMMENDATIONS FOR FUTURE WORK}

Because most of the work to date in applying the endochronic theory of viscoplasticity is restricted to uniaxial stress or strain cases, it seems logical to extend into multidimensional problems. As can be seen from the previous discussion, wave propagation problems can serve as a rigorous test for constitutive laws under dynamlc loading conditions; therefore, the combined multidimensional viscoplastic wave propagation will suit the purpose.

Many of the engineering materials are used at elevated temperatures (nuclear power plant components, high-temperature turbines, etc.). To correctly model the mechanical response of those structural components at extreme load, we must study mechantcal behavior under high-temperature conditions. Again the endochronfc formulations would be a good candidate for those investigations. Once the temperature and high strain-rate effects can be modeled, then it will be possible to study interaction between thermal and mechanical coupling (e.g. thermal stress problems in solidification and melting, etc.).

Another area in mechanics research that 1s attracting much attention is the problem of fracture and fatigue. It seems ideal to utilize the concept of intrinsic time measure to predict the fatigue life of structural components, to relate the intrinsic time to fracture criteria, and to employ it as a scale of damage accumulation.

Concerning numerical technique, the endochronic theory has been used with finite-difference methods, finite-element methods, and methods of characteristics. For more complicated geometries, it appears that the finite-element method is most versatile. It is quite feasible to apply the developed endochronic formulations to all structural problems for which conventional plasticity has been used. This would include limit analyses; optimal design, shakedown analyses, and stability of elastiomplastic equilibrium problems. The latter application is of importance in problems involving fluid-structure interactions. 


\section{SUMMARY AND CONCLUDING REMARKS}

Effort in this project was concentrated on the development and application of the dynamic aspects of endochronic theory. Specifically, the following was accomplished:

- Numerical calculation for various dynamic structural response problems were performed using simple endochronic theory and the results were compared with classical plasticity theory and/or experiments.

- Uniqueness and stability problems of the simple endochronic theory arising from dynamic applications were studied.

- The improved endochronic formulation was extended to include strain rate effects and was applied to wave propagation problems.

The analyses that have been performed comparing classical and endochronic theory have shown that in many cases the endochronic approach can result in a substantial reduction in computational time, with equivalent solution accuracy. This result, combined with the apparent accuracy of the material representation, indicates that the use of endochronic plasticity has great potential in the evaluation of the dynamic response of structural systems. It is anticipated that the saving in computer time noted in these initial examples will also be realized in more complex cases. This judgement is based on the fact that the numerical complexity associated with the method does not increase as one 'moves to more general or complex problems. This is in contrast with classical plasticity, where complexities associated with a multidimensional yield surface exist.

It has been shown that the endochronic theory of viscoplasticity can uniquely predict many dynamic structural problems at least as well as the classical plasticity theory without numerical difficulties or instabilities. This was demonstrated in various numerical examples and by theoretical analysis. As the theory evolved from the simple endochronic formulation to the improved endochronic theory, it was also shown that although the improved theory can have an initlal yield surface, one can chose material parameters that approximate the classical elastic unloading within accepted engineering accuracy yet without introducing a discontinuity into the numerical couputation. Thus, the advantage of the simple endochronic theory is preserved in the improved version, as was demonstrated in the study of the wave propagation problems. 


\section{ACKNOWLEDGMENTS}

The valuable comments and encouragement by Drs. C. A. Kot and G. S. Rosenberg are gratefully acknowledged. The support by Dr. Oscar Manley, Office of Basic Energy Sclences, U. S. Department of Energy, is greatly appreciated. The author gratefully acknowledges the efforts of all those who contributed to this project. . They include Dr. B. J. Hsieh, R. A. Valentin, Prof. W. Edelstein of I.I.T., and Prof. H. C. Wu of the University of Iowa. 


\section{REFERENCES}

1. K. C. Valanis, "A Theory of Viscoplasticity without a Yield Surface, Part I: General Theory, Part II: Application to Mechanical Behavior of Metal," Arch, Mech. Stosow. 23: 517-555 (1971).

2. K. C. Valanis, "Fundamental Consequences of a New Intrinsic Time Measure-Plasticity as a Limit of the Endochronic Theory," Arch. Mech. 32: 171-191 (1980).

3. I. S. Sandler, "On the Uniqueness and Stability of Endochronic Theories of Material Behavior," J. Appl. Mech. 45: 263-266 (1978).

4. R. S. Rivlin, "Some Comments on the Endochronic Theory of Plasticity," Int. J. Solids Structures 17: 231-248 (1981).

5. H. C. Lin, B. J. Hsieh, and R. A. Valentin, "The Application of Endochronic Plasticity Theory in Modeling the Dynamic Inelastic Response of Structural Systems," Nuc1. Eng. Des. 66: 213-222 (1981).

6. B. J. Hsieh, "F.E.M. Analysis of Impact/Penetration Problems," Vo. 4, 2nd ASCE Conference on Civil Engineering and Nuclear Power Proceedings, Knoxville, Tennessee, Sept. 15-17, 1980.

7. H. C. LIn, "Dynamic Propagation of Longitudinal Cracks in a Pressurized Cylindrical Shell due to Ductile Fallure," Nucl. Eng. Des. 63: 137-142 (1981).

8. H. C. Lin, "Dynamic Plastic Deformation of Ax1-Symmetric Circular Cylindrical Shells," Nucl. Eng. Des. 35: 283-293 (1975).

9. H. C. Lin, "Dynamic Inelastic Response of Thick Shells Using Endochronic Theory and the Method of Nearcharacteristics," 13th Annual Meeting, Soclety of Engineering Science, NASA CP-2001, 2: 449-458 (1.976).

10. B. J. Hsieh, "Application of Endochronic Theory in Mult1-dimensional Stress States," Nucl. Eng. Des. 63: 143-155 (1981).

11. B. J. Hsieh, "On the Uniqueness and Stability of Endochronic Theory," J. App1. Mech. 47: 748-754 (1980).

12. W. S. Edelstein, "A Review of Some Endochronic Theories and Their Applications," ANL-CT-82-22 (Nov. 1982).

13. H. C. Lin and H. C. Wu, "On the Improved Endochronic Theory of Viscoplasticity and Its Application to Plastic-Wave Propagation," ANL-CT-81-37 (Oct. 1981).

14. H. C. Lin and H. C. Wu, "Plastic Wave Propagation of Rate-Sensitive Material Using New Intrinsic Time," Proceedings of the Ninth U.S. National Congress of Applied Mechanics, ASME, p.468 (June 1982). 


\section{REFERENCES (cont'd)}

15. H. C. Lin and H. C. Wu, "Viscoplastic Wave Propagation of Endochronic Theory," Development in Mechanics, Vol. 12, Proceedings of the 18th Midwestern Mechanics Conference, pp. 35-36 (1983).

16. H. C. LIn and H. C. Wu, "On the Rate Dependent Endochronic Theory of Viscoplasticity and Its Application to Plastic-Wave Propagation," Int. J. Solids Structures. (In press.) 


\section{APPENDIX}

\section{PROJECT PUBLICATIONS}

1. B. J. Hsieh, "The Use of Endochronic Plasticity for Multidimensional Small and Large Strain Problems," ANL-CT-79-19 (1980).

2. H. C. Lin, "Dynamic Propagation of Longitudinal Cracks in a Pressurized Cylindrical Shell Due to Ductile Failure," ANL-CT-80-27 (July 1980).

3. B. J. Hsieh, "F.E.M. Analysis of Impact/Penetration Problems," VOL. 4, 2nd. ASCE Conference on Civil Engineering and Nuclear Power Proceedings Knoxville, Tennessee, Sept. 15-17, 1980.

4. B. J. Hsieh, "On the Uniqueness and Stability of Endochronic Theory," Trans ASME, J. App1. Mech., 47 (4): 748-754 (Dec. 1980).

5. H. C. Lin, "Dynamic Propagation of Longitudinal Cracks in a Pressurized Cylindrical Shell due to Ductile Failure," Nucl. Eng. Des. 63: 137-142 (1981).

6. B. J. Hsieh, "Application of Endochronic Theory in Multi-dimensional Stress States," Nuc1. Eng. Des. 63: 143-155 (1981).

7. H. C. Lin, B. J. Hsleh, and R. A. Valentin, "The Application of Endochronic Plasticity Theory in Modeling the Dynamic Inelastic Response of St ructural Systems, "Nucl. Eng. Des. 66: 213-222 (1981).

8. H. C. Lin, and H. C. Wu, "On the Improved Endochronic Theory of Viscoplasticity and Its Application to Plastic-Wave Propagation," ANLCT-81-37 (Oct. 1981).

9. H. C. Lin, and H. C. Wu, "Plastic Wave Propagation of Rate-Sensitive Material Using New Intrinsic Time," Proceedings of the Ninth U.S. National Congress of Applied Mechanics, ASME p. 468 (June 1982).

10. W. S. Edelstein, "A Review of Some Endochronic Theories and Their Applications," ANL-CT-82-22 (Nov. 1982).

11. H. C. Lin, and H. C. Wu, "Viscoplastic Wave Propagation of Endochronic Theory," Development in Mechanics, Vo1. 12, Proceedings of the 18th Midwestern Mechanics Conference, pp. 35-36 (1983).

12. H. C. LIn, and H. C. Wu, "On the Rate Dependent Endochronic Theory of Viscoplasticity and Its Application to Plastic-Wave Propagation," Int. J. Solids Structures. (In press.) 
Distribution for ANL-83-59

Internal
E. S. Beckjord
G. S. Rosenberg
K. L. Kliewer
S. K. Zussman
C. E. Ti11
C. A. Kot
R. A. Valentin
W. Edelstein
E. J. Croke
H. C. LIn (58)
B. R. T. Frost
C. K. Youngdahl
R. A. Lewis
M. G. Srinivasan
K. D. Kuczen
T. J. Moran
D. R. Henley
B. J. Hs Ieh
R. S. Zeno
K. F. Kasza
P. $\bar{R}$. Huebotter
M. W. Wambsganss

S. S. Chen

R. W. Weeks

F. U. Kocks

S. H. Fistedis

J. M. Kennedy

Y. Chang

R. F. Kulak ANL Patent Dept. ANL Contract File ANL Lubräries (3)

External:

DOE/TIC, for distribution per UC-25 (197)

Manager, Chicago Operations office, DOE

V. H. Hummel, DOE-CH

o. Manley, Office of Basic Energy Sciences, DOE (3)

Components Technology Division Review Committee:

A. A. Bishop, U. Pittsburgh

F. W. Buckman, Consumers Power Co.,, Jackson, MI

R. A. Greenkorn, Purdue University

W. M. Jacob1, Westinghouse Electr1c Corp., P1ttsburgh

R. Cohen, Purdue University

E. E. Ungar, Bo1t, Beranek, and Newman, Inc., Cambridge, MA

J. Weisman, University of Cincinnati 